\title{
Improving the Quality of Teacher Services by Revitalizing Servant Leadership, Self-Efficacy and Job Satisfaction
}

\author{
Rismurdiyati*, Soewarto Hardhienata, Rita Retnowati, MS \\ Pakuan University Bogor, Indonesia
}

*Corresponding Author: Rismurdiyati, Pakuan University Bogor, Indonesia

\begin{abstract}
This study aims to determine the effect of servant leadership, self-efficacy and job satisfaction in improving the quality of teacher services. This study uses a correlational research method. The number of samples was 294, and respondents were determined using the Slovin formula from a total population of 1,097 State Junior High School teachers in the City Area of North Jakarta Administration. Sampling is done by proportional random sampling. Data from the results of this study were analyzed using the SITOREM (Scientific Identification Theory to Conduct Operation Research in Education Management)to make recommendations and determine the order of priority for improvements that need to be made. The research data was taken by distributing questionnaires and analyzed using regression analysis and supported by statistical descriptions. Qualitative data were collected using interviews, observation and documentation aimed at identifying qualitative research results. The findings obtained from the study which strengthened the results of this qualitative study are: There is a significant positive relationship and is strengthened by the results of qualitative research between 1). Leadership serves with service quality with a correlation coefficient ryl $=0.37752$ ). Self-efficacy with service quality with a correlation coefficient ry2 $=0.4663,3$ ). job satisfaction with service quality with a correlation coefficient ry3 $=0.526$, 4). Service leadership and selfefficacy together with service quality with a correlation coefficient ry120.450 =, 5). a leadership serves and job satisfaction together with service quality with a correlation coefficient ry130.233=, 6), self-efficacy and job satisfaction together with service quality with a correlation coefficient ry23=0.220, and 7), servant leadership, self-efficacy and job satisfaction together with service quality with a correlation coefficient ry123=0.991. Based on the data above, to improve service quality can be done by increasing leadership in serving, self-efficacy and job satisfaction, both individually and together. Not maximally achieving improvement in service quality indicates other factors that affect service quality.
\end{abstract}

Key words: servant leadership, self-efficacy, job satisfaction, service quality and analysis of systems.

\section{INTRODUCTION}

All children have the right to study and obtain a quality education, at the level of formal or non-formal units. Each teacher is expected to have a good understanding of the diversity of the individual conditions of their students, to be able to provide educational services that are appropriate to the needs and uniqueness of the child. This is following the Ministry of Education Regulation No. 70 of 2009 concerning the Implementation of Inclusive Education. The purpose of education is to educate the nation's life or produce quality human resources, both scientifically, knowledge, skills and personality.

Along with the demand for quality education services to overcome the above problems, the government has made many efforts and alternative policies. Some of them are organizing flagship schools, model schools, integrated schools and others. In addition, studies and studies on efforts to improve the quality of education have also been carried out, including the concept of SBM (SchoolBased Management) and school management with environmental perspectives.

If the quality of teacher services is low, the learning process is not optimal. As a result, students get their learning not optimal, which means that if students graduate, the quality of student graduation is not as expected in educational goals. For example, the quality of educational services is the main key to realizing achievement in various fields. Without a minimum quality service equivalent to a minimum standard of service in the field of education, it is very difficult to achieve maximum achievement. The results of a preliminary survey of the quality of services to state teachers as many as 
30 people were taken at random with the principal respondent in the administrative area of the city of North Jakarta, giving the following picture:

a. There are $62 \%$ of teachers who have problems with service quality in thedimensiontangible, especially in the case of teachers using teaching materials based on the syllabus of subjects and teachers providing remedial learning for students who are judged to be lacking.

b. There are $65 \%$ of teachers who have problems in the quality of service in the dimension of reliability, particularly in terms of learning in the classroom Teachers begin as scheduled set time and teachers completed the study after completion of teaching administration.

c. There are $63 \%$ of teachers who have problems with service quality in the dimension of customer response (responsiveness), especially in the case of teachers together with all students carrying out religious activities at school and teachers calling parents of students who have problems.

d. There are $67 \%$ of teachers who have problems in the quality of service in the dimensions of a guarantee (assurance), especially in the case of the teacher helps the student task - a task that is considered difficult and teacher to plan activities of deepening of the material to parents.

e. There are $67 \%$ of teachers who have problems with service quality in the dimension of giving empathy (empathy), especially in terms of teachers preparing learning tools to support teaching and learning activities and teachers look neat when teaching and when in the school environment.

Based on the preliminary survey data above, the condition can be seen that the quality of service among teachers in the State Junior High School of North Jakarta City Administration is still problematic. Therefore, serious handling is needed so that the quality of service becomes better. However, the improvement as mentioned above requires considerable time and serious handling through harmonizing the cooperation of all parties in a compact and sustainable manner due to many factors that contribute to improving the service quality. Among the many factors referred to, according to the results of observations in the field of leadership factors serving, self-efficacy and job satisfaction are the most dominant factors and need to be further investigated because the improvement of these factors will provide an increase in the quality of service better and optimally considering so far the factors - the factors above have not yet shown any indication of the connection that leads to the achievement of educational goals.

Based on the description of the problem above, the problem formulation can be arranged as follows:

1. Is there a relationship between servant leadership and the quality of teacher services?

2. Is there a relationship between self-efficacy and the quality of teacher services?

3. Is there a relationship between job satisfaction with the quality of teacher services?

4. Is there a relationship between servant leadership, self-efficacy and job satisfaction together with the quality of teacher services?

\section{LITERATURE REVIEW}

\subsection{Quality of Service}

Harris (2011), in his research, suggests that the quality of service is a comparison between the quality of services received after receiving the expected quality. The indicators are 1. Reliability, consistent in providing services, 2. Responsiveness, responsiveness in providing services, 3. Assurance, guarantee in providing services, 4. Empathy, careful attention to user needs, 5. Tangibles, infrastructure facilities and service facilities provided.

In line with this, Boyd (2011) argues that service quality is an effort that can be used to analyze gaps that occur in the service quality performance of an organization with the needs of the quality of user services. As for the indicators are 1. Tangibles, (physical appearance), concerning the physical appearance of service facilities, equipment or equipment, and corporate human resources, 2 . Responsiveness (responsiveness), regarding the willingness and ability of service providers to respond to their requests immediately, 3. Assurance (guarantee of trust), concerning the ability to foster consumer trust and confidence, 4. Empathy (attention to consumers) provides personal attention to users, 5: reliability (reliability/constancy), organizations to deliver the promised service accurately and quickly. 


\subsection{Servant Leadership}

Orphanos (2014) suggests that servant leadership theory is based on service to others and the recognition that the role of organizations is to create people who can build a better future, experts, practitioners who respond to perceptions that develop where its characteristics are: 1 -listening, 2. Empathy, 3. Recovery, 4. Self-awareness, 5. Persuasion, 6. Conceptualization, 7. Foresight, 8. Arranging services, 9. Commitment to trust, 10. It is building a community in maintaining wholeness.

According to Shek (2015), it is argued that servant leadership focuses on the role of the leader in his relationship with followers, built through the allocation of opportunities for followers to help him grow and develop. Its characteristics are 1. Empowerment, empowerment of motivation, 2. Accountability, control and responsibility actions, 3. Standing back, prioritizing the interests of others, 4. Humility, putting achievements and talents in the right perspective, 5. Authenticity, the true state, 6. Courage, dare to take a new approach in a proactive, innovative and creative manner, 7 . Interpersonal acceptance, understanding feelings and alleviating problems, 8.Stewardship, willingness to take responsibility.

Based on the theoretical study above, it can be synthesized that leadership serves is the behaviour of leaders who focus on managing the organization for career development and services to create a conducive climate for work and make changes for the progress of the organization they lead. The indicators of servant leadership can be synthesized from a variety of theories above, including 1.attentively (listening), 2. Trying to understand (strives to understand), 3. Efforts to restore emotional relationships (emotional healing ),4. Self-awareness, 5. The ability to influence others (persuasive mapping), 6. Thinking Conceptualization perspective (conceptualization), 7. Outlook for the future (foresight), 8. Structuring services to the organization (organizational stewardship), 9. commitment to personal growth (commitment to the growth of people),10. Establish community motivation (community-building).

\subsection{Self-Efficacy}

Mojo Vezi (2012) argues that the teacher's self-efficacy is a person's beliefs about his ability to organize and take action needed to complete tasks and be able to influence choices in action, the amount of effort done and the level of business persistence in the form of motivation or enthusiasm. There are four characteristics of the determinants that affect the level of one's self-efficacy, namely: 1 . Previous performance experience, 2. Learning from experience, 3. Verbal persuasion, meaningful messages, and 4. Controlled emotional state.

According to Viel (2010), self-efficacy is the confidence that a person has to work well in certain situations. Its characteristics are 1: magnitude, the magnitude of the task level, 2. Strength, holding on to the strength of belief, 3. Generality, the extent to which expectations are generalized in all situations and conditions.

Based on some theoretical studies above, it can be synthesized that self-efficacy is an individual's belief in his ability to organize, work, and complete tasks according to their responsibilities with a certain level of success to give good results. These successes include organizing, doing and completing tasks according to their responsibilities with a certain level of success so that it gives the best results because it is influenced by the experience possessed and forms a strong personality and is tested by various obstacles that occur, situations and conditions that shape increasingly become a reality.

\subsection{Job Satisfaction}

Colquitt Doghnaze (2012) formulates job satisfaction as an emotional state of an individual arising from an assessment of his work, or experiences at work. There are 5 (five) factors that most individuals want to obtain or enjoy while working, namely: a. salary (high and certain), b. promotion (opportunity based on performance and ability), c. Boss supervision (a good working relationship with the boss, and the award), d. coworkers (good and responsible relationship), and e. the work itself (the freedom to realize abilities, creations, achievements, etc.).

Meanwhile, according to Theresia (2018), job satisfaction is a general attitude of an individual towards his job. There are 4 (four) factors that affect job satisfaction: a. challenging jobs, jobs that 
provide opportunities to use skills and abilities and provide a variety of tasks, freedom and feedback about how well they work, b. Appropriate rewards, employees want a fair payment system, unambiguous and in line with employee expectations, c. supportive working conditions, related to a comfortable work environment and ease of doing work (spatial planning, clean workspace, facilities and assistive devices, temperature and noise level), d. Supportive colleagues, such as mutual respect, loyalty and tolerance between one another, open attitude and intimacy between employees.

\section{METHOD}

This study included all North Jakarta City Region Middle School Teacher, totalling 1097 teachers. This study uses a combination of research methods (mixed methods). Mixed methods are research methods that combine two or more methods in the process of gathering and analyzing research. Research data collection is carried out by distributing questionnaires to respondents who have been selected as samples. The results of the questionnaire were collected and recorded to analyze the data to test the research hypotheses and to find out the strength of the relationship between organizational climate, transformational leadership and interpersonal communication with job satisfaction. The data analysis technique used in this study is descriptive and inferential data analysis techniques. Descriptive statistics, namely statistical science that can present data through the most important and relevant data collection and summary to be included in the data analysis tool. While inferential statistics, namely statistical science that acts as a data analysis tool that has been presented in descriptive statistics.

In this study, the Qualitative Recommendation analysis method is used to supplement the results of Quantitative Research. Implementation of Qualitative Research Methods Conducted using the SITOREM Method. SITOREM stands for "Scientific Identification Theory to Conduct Operations Research in Educational Management", which in general can be interpreted as a scientific method used to identify variables (theory) to carry out "Operational Research" in the field of Education Management (Hardhienata, 2017).

\section{RESULTS AND DISCUSSION}

\subsection{Relationship Between Servant Leadership and Teacher Service Quality}

Based on the results of hypothesis testing, it shows that there is a functional relationship between servant leadership and service quality with the resulting correlation coefficient value of $r_{\mathrm{y} 1}=0.3775$. This shows that leadership serves influence by $37.75 \%$ of the quality of teacher services, while $62.25 \%$ is influenced by other factors. Besides, the value also shows that the strong relationship between servant leadership and teacher service quality is relatively low; however, any increase in servant leadership score will improve service quality.

This relationship is strengthened by the partial correlation coefficient between servant leadership and service quality with controlling the self-efficacy variable obtained by the correlation coefficient $r_{y 1.2}=$ 0.212. Then based on the calculation of the Partial Correlation Test with the variable work satisfaction, the value of robtained $\mathrm{y}_{1.3}=0.308$ is. The data implies that the relationship of servant leadership with service quality is significant even though the variable of servant leadership is controlled by the variables of self-efficacy and job satisfaction. The findings obtained in this study indicate that servant leadership is a form of interaction that must always be realized in a good and harmonious way between service providers and their customers so as to improve service quality.

Data from the qualitative research of the service quality variables above that have been analyzed are also strengthened with data from observations, interviews and documentation. For service quality variables through qualitative research activities, it can be concluded that: the relationship between leadership service variables and the quality of teacher services is qualitatively relatively low because based on the results of the FGD, the reality is that leadership serving, in this case, is the principal giving less attention to both teachers and school residents existing, not optimal in providing services to the needs of teachers and students, not so listening to complaints of the school residents who are fostered and do not care about the environment, lacks tolerance and unable to commit to the progress of others, however, the service quality variable obtained through quantitative research has the same tendency with service quality data obtained through qualitative research. So that qualitative research data corroborates the results of quantitative research conducted previously. 
The results of previous studies conducted Gelfuso (2014) by concluded that there was a significant positive relationship $(r=0.660 ; p<0.001)$ between servant leadership and service quality, thus leadership serves to contribute greatly in determining the quality of service in an organization or work unit.

Based on the description above, it can be concluded that the better the leadership serves, the more the quality of service increases. Thus the findings of facts and data in the analysis of this study further support the previous findings regarding the positive relationship between leadership in serving with service quality.

\subsection{The Relationship Between Self-Efficacy and Teacher Service Quality}

Based on the results of hypothesis testing, it shows that the coefficient of determination between the teacher's self-efficacy and service quality is $r_{y 1}{ }^{2}=0.2174$. This means that $21.74 \%$ of service quality is the result of the workings of the teacher's self-efficacy variable. In comparison, $78.26 \%$ is contributed by other variables that have a relationship with service quality improvement. The findings obtained in this study indicate that self-efficacy is a person's belief about his ability to do and complete tasks in accordance with their responsibilities with a certain level of success so that it can directly or indirectly improve service quality.

The qualitative research data results of the above self-efficacy variables that have been analyzed are strengthened by the data of observations, interviews and documentation, for the self-efficacy variables it can be concluded that: the relationship between the self-efficacy variable and the quality of the teacher's service is qualitatively relatively lacking because based on the FGD results from the fact self-efficacy which in this case is attached to a teacher who has low competence, lacks mastering pedagogic, has low personal and social competence, resulting in the teacher lacking confidence in his abilities and unable to adapt to the existing environment so that the teacher is difficult to invited to change. It is very difficult to accept various input because they feel as seniority. However, the data of self-efficacy variables obtained through quantitative research have the same tendency with selfefficacy data obtained through qualitative research. So that qualitative research data corroborates the results of quantitative research conducted previously.

Based on the description above, it can be concluded that the better and more conducive self-efficacy, the better the quality of service. Thus the findings of facts and data in the analysis of this study further support previous findings regarding the existence of a positive relationship between self-efficacy and service quality.

\subsection{Relationship Between Job Satisfaction and Teacher Service Quality}

Based on the results of hypothesis testing, it shows that the coefficient of determination between teacher job satisfaction and service quality is $\mathrm{r}_{\mathrm{y} 3}{ }^{2}=0.2769$. This means that $27.69 \%$ of service quality is the result of the work performance of teacher job satisfaction variables. In comparison, $72.31 \%$ is contributed by other variables that have a relationship with service quality improvement. The findings obtained in this study indicate that job satisfaction is positive and pleasant emotional states that result from rewarding one's work in order to improve service quality.

The results of previous studies conducted by Malik (2010) study stated that job satisfaction contributed $66,462 \%$ to service quality. Means that there is a significant positive relationship between Job Satisfaction with service quality with $(\mathrm{r}=0.815 ; \mathrm{p}<0.05)$. The higher job satisfaction is predicted to be the higher the quality of services provided.

The qualitative research data results of the above job satisfaction variables that have been analyzed are also strengthened by the data from observations, interviews and documentation for the variable job satisfaction can be concluded that: the relationship between the variable job satisfaction with the quality of teacher services is qualitatively sufficient because based on the results of the FGD obtained the fact that if a the teacher has been satisfied because of his efforts in carrying out his duties and responsibilities such as salary received on time and in accordance with the rank and class so that it can be sufficient for his life, everything that is done in accordance with the duties and responsibilities so that it does not become a burden in the routine work, get a promotion in accordance with the career path for his position, noticed by superiors both in the form of health and welfare for his family, have colleagues who always support and provide encouragement and sportsmanship in establishing soli 
safety and work environment that is safe and comfortable so that they can carry out their duties and work calmly and the creation of a conducive work environment so that it is evident that data on job satisfaction variables obtained through quantitative research have the same tendency with job satisfaction data obtained through qualitative research. So that qualitative research data corroborates the results of quantitative research conducted previously (Rajiani,2010).

Based on the description above, it can be concluded that better job satisfaction, the better the quality of service. Thus the findings of facts and data in the analysis of this study further support previous findings regarding the existence of a positive relationship between job satisfaction with service quality.

\subsection{The Relationship Between Servant Leadership, Self-Efficacy and Job Satisfaction with Service Quality}

Based on the results of hypothesis testing, the coefficient of determination between servant leadership, self-efficacy and job satisfaction together with service quality is $\mathrm{r}_{\mathrm{y} 123}{ }^{2}=0.991$. This means that $99.1 \%$ of service quality is the result of the work of leadership variables serving, self-efficacy and job satisfaction together, while $0.9 \%$ is contributed by other variables that have a relationship with improving the service quality.

The findings in this study are that through servant leadership coupled with an increase in self-efficacy and with the achievement of maximum job satisfaction will improve optimal service quality. Servant leadership is a unique style of leadership ideology that runs contrary to the nature of human behaviour that is selfish. This happens because there is maximum support from self-efficacy that is built so that people who have confidence about their ability to organize and complete a task that is needed to achieve certain results in various forms and levels of difficulty. Individuals with high self-efficacy have a feeling of being able to work, work well, enjoy challenges, and work diligently (learning). The combination of servant leadership and well-organized self-efficacy will be able to determine targets that must be achieved more realistically so as to lead to maximum job satisfaction.

This is consistent with the theory put forward by Rauch, K., E. (2007: 12), that servant leadership is the perception of leaders who perceive that they are the main stewards. A leader according to Rauch, K., E. must realize that he must is the first and foremost person in carrying out acts of service so that the person he leads is able to follow what he does. The main factors servant leadership there are four, namely: a. Authenticity, b. valuing people (appreciation of people), c, developing people (development people), d. building community (development), e. providing leadership (preparation of leaders), and f. sharing leadership (sharing leadership).

Based on the description above, it can be concluded that the higher the application of leadership in serving, self-efficacy and job satisfaction will increase the quality of service. Thus the findings of facts and data both quantitative and qualitative research results in the analysis of this study tend to further support previous findings regarding the relationship between servant leadership, self-efficacy and job satisfaction with service quality.

The results of the application of leadership serve in conducive self-efficacy and in job satisfaction of members of a good organization, the achievement of increasing service quality is very significant up to $99.1 \%$ while an increase of $0.9 \%$ to the achievement of service quality is achieved by using other variables that are related to service quality variables both directly and indirectly.

Other factors which also related to $0.9 \%$ revealed through the focus of qualitative research area. Teacher competence is not optimal, both in terms of social, pedagogical, professional and personality competencies that cause teachers to have no confidence in acting in their fields. b. Job Description and Division of work tasks that must continue to be refined in accordance with the appropriate expertise and educational background. c. A work culture which must continue to be conducive in order to avoid conflicts between people and create better harmonization of work. d. Commitment to organizations that still need to be fostered and developed in a more directed and embedded as a form of full awareness for members of the organization so that they are able to position themselves in accordance with their respective duties, and must continue to be optimized through various innovations and trials of various new methods in accordance with the times that are happening, so keep it up to date and don't miss it (Rajiani, 2011). 


\section{SiTOREM ANALYSIS}
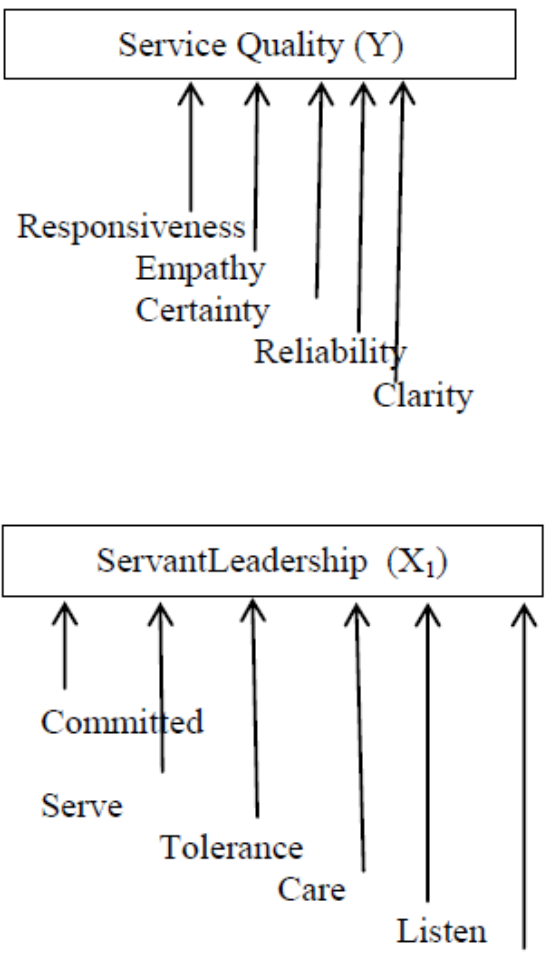

Pay attention to

\section{WEIGHING AND INDICATOR SCORES}

1. Responsiveness $(22,5 \%)(3,836)$

2. Empathy $(22,5 \%)(4,372)$

3. Certainty $(20 \%)(4,551)$

4. Reliability $(17,5 \%)(4,472)$

5. Clarity $(17,5 \%)(3,949)$

$\mathrm{R}=0.3775$

\section{WEIGHING AND INDICATOR SCORES}

1. Committed $(23,53 \%)(4,293)$

2. Serve $(21,18 \%)(4,227)$

3. Tolerance $(14,12 \%)(4,158)$

4. Care $(14,12 \%)(3,981)$

5. Listen $(14,12 \%)(4,111)$

6. Pay attention to $(12,94 \%)(4,661)$

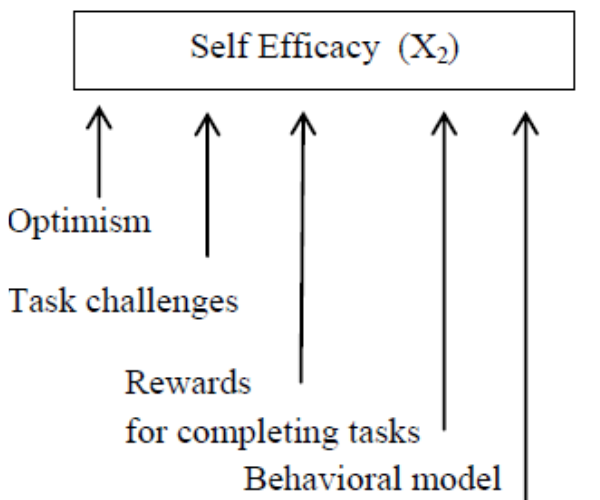

$\mathrm{R}=0.4663$

WEIGHING AND INDICATOR SCORES

1. Optimism (15.0\%) $(3,827)$

2. Task challenges $(13.33 \%)(4,565)$

3. Rewards for completing tasks $(13.33 \%)(4,143)$

4. Behavioral model $(13.33 \%)(4,204)$

5. Prestige $(11.67 \%)(4,197)$

$$
\mathrm{R}=0.5262
$$

\section{WEIGHING AND INDICATOR SCORES}

1. Salary $(23 \%)(4,1)$

2. Promotion $(22 \%)(4,1)$

3. Co-workers $(21 \%)(3,8)$

4. Profession $(18 \%)(4,1)$

5. Supervision of superiors $(16 \%)(4,0)$

Figure1. Analysis of SITOREM (Scientific Identification Theory for Operational Research in Education

\section{CONCLUSiON}

This study was conducted with the aim of finding efforts to improve teacher services quality through the development of Strengthening Leadership in Serving, Self-Efficacy and Job Satisfactionof Middle School in North Jakarta. The effort was made by identifying the strengths of the relationship between these variables. Based on the results of the analysis, discussion of research results and hypotheses that have been tested, it can be concluded as follows: 
1. There is a positive relationship between the servant leadership and teacher services quality, with a correlation coefficient of $r_{y 1}=0.37754$ or $37.754 \%$. The results of qualitative research show the same thing. This shows that the higher the leadership in serving, will higher the teacher services quality and vice versa.

2. There is a positive relationship between the self-efficacy and teacher services quality, with a correlation coefficient of $\mathrm{r}_{\mathrm{y} 1}{ }^{2}=0.2174$ or $21.74 \%$. The results of qualitative research show the same thing. This shows that the higher the self-efficacy, will higher the teacher services quality and vice versa.

3. There is a positive relationship between job satisfaction and teacher services quality, with a correlation coefficient of $\mathrm{r}_{\mathrm{y} 3}{ }^{2}=0.2769$ or $27.69 \%$. The results of qualitative research show the same thing. This shows that the higher the job satisfaction, will higher the teacher services quality and vice versa.

4. There is a positive relationship between the servant leadership, self-efficacy and job satisfactiontogether with teacher service quality with a correlation coefficient of 0.991 or $99.1 \%$. This indicates that teacher service quality can be improved through strengthening the servant leadership, self-efficacy and job satisfaction.

\section{REFERENCES}

[1] Boyd, D., Lankford, H., Loeb, S., Ronfeldt, M., \& Wyckoff, J. (2011). The role of teacher quality in retention and hiring: Using applications to transfer to uncover preferences of teachers and schools. Journal of Policy Analysis and Management, 30(1), 88-110.

[2] Doghonadze, N. (2012). A survey on university lecturer job satisfaction. Journal of Education, 1(1), 17-22.

[3] Gelfuso, A., \& Dennis, D. V. (2014). Getting reflection off the page: The challenges of developing support structures for pre-service teacher reflection. Teaching and teacher education, 38, 1-11.

[4] Hardhienata, S., 2017.The development of scientific identification theory to conduct operation research in education management. In IOP Conference Series: Materials Science and Engineering (Vol. 166, No. 1, p. 012007). IOP Publishing.

[5] Harris, DN, \& Sass, TR (2011). Teacher training, teacher quality and student achievement. Journal of public economics, 95(7-8), 798-812.

[6] Malik, M. E., Danish, R. Q., \& Usman, A. (2010). The impact of service quality on students' satisfaction in higher education institutes of Punjab. Journal of Management Research, 2(2), 1-11.

[7] Mojavezi, A., \& Tamiz, MP (2012). The Impact of Teacher Self-efficacy on the Students' Motivation and Achievement. Theory \& Practice in Language Studies, 2(3).

[8] Orphanos, S., \& Orr, MT (2014). Learning leadership matters: The influence of innovative school leadership preparation on teachers' experiences and outcomes. Educational Management Administration \& Leadership, 42(5), 680-700.

[9] Rajiani, I., \& Jumbri, I. A. (2011). The cultural ecology of new public management in Indonesia. Journal of Administrative Science, 8(1), 17-31.

[10] Rajiani, I. (2010). Applying Personality Traits to Predict Loyalty and Neglect among Employees of Bank Jatim Located in 10 Big Cities of East Java (Mc Crae's and Hofstede's Theories on the effect of Culture on Personality Revisited). Jurnal Aplikasi Manajemen, 8(3), 617-622

[11] Shek, DT, Yu, L., \& Siu, AM (2015). Interpersonal competence and service leadership. International Journal on Disability and Human Development, 14(3), 265-274.

[12] Theresia, L., Lahuddin, A. H., Ranti, G., \& Bangun, R. (2018). The influence of culture, job satisfaction and motivation on the performance lecturer/employees. In International Conference on Industrial Engineering and Operations Management. Bandung (pp. 2541-2552).

[13] Viel-Ruma, K., Houchins, D., Jolivette, K., \& Benson, G. (2010). Efficacy beliefs of special educators: The relationships among collective efficacy, teacher self-efficacy, and job satisfaction. Teacher Education and Special Education, 33(3), 225-233.

Citation: Rismurdiyati, et.al. "Improving the Quality of Teacher Services by Revitalizing Servant Leadership, Self-Efficacy and Job Satisfaction" International Journal of Managerial Studies and Research (IJMSR), vol 8, no. 7, 2020, pp. 80-87. doi: http:// dx.doi.org/10.20431/2349-0349.0807010.

Copyright: (c) 2020 Authors. This is an open-access article distributed under the terms of the Creative Commons Attribution License, which permits unrestricted use, distribution, and reproduction in any medium, provided the original author and source are credited. 